\title{
Partial hepatectomy in a Plains garter snake (Thamnophis sirtalis radix) with biliary cystadenoma: case report
}

\author{
Zdeněk Knotek ${ }^{1,2}$, Elvira Grabensteiner ${ }^{2}$, Zora Knotková ${ }^{1}$, Anna Kübber-Heiss ${ }^{3}$, \\ Gerald Benyr ${ }^{4}$ \\ ${ }^{1}$ University of Veterinary and Pharmaceutical Sciences, Faculty of Veterinary Medicine, \\ Avian and Exotic Animal Clinic, Brno, Czech Republic \\ ${ }^{2}$ University of Veterinary Medicine, Clinic for Avian, Reptile and Fish Medicine, \\ Department for Farm Animals and Veterinary Public Health, Vienna, Austria \\ ${ }^{3}$ University of Veterinary Medicine, Institute of Pathology and Forensic Veterinary Medicine, \\ Department of Pathobiology, Vienna, Austria \\ ${ }^{4}$ Natural History Museum Vienna, Abteilung für Ökologie, Sektion für Vivaristik, Vienna, Austria
}

Received October 8, 2010

Accepted October 23, 2012

\begin{abstract}
A four-year-old, captive-bred, female Plains garter snake (Thamnophis sirtalis radix) was presented with a large midbody distension $(5 \mathrm{~cm} \times 3 \mathrm{~cm} \times 3 \mathrm{~cm})$ in the second third of the body length (total body length $123 \mathrm{~cm}$ ). Contrast radiography technique excluded an envolvement of the oesophagus or stomach. Aspiration of $8 \mathrm{ml}$ of acellular straw coloured fluid negative for presence of bacteria, fungi or parasites, reduced the swelling to a third of its original size. Surgical exploration revealed a pathologically changed central part of the liver with multiple different sized cysts. Histopathologically the diagnosis was defined as biliary cystadenoma. As the liver had a physiological appearance cranial and caudal to the central area, a partial hepatectomy was performed. The snake recovered well and started to feed spontaneously two days after surgery. During the check up two, four and seven months after hepatectomy, the snake was active and in a good condition. Hypoproteinaemia and altered activity of lactate dehydrogenase were present two months after surgery, azurophilia and hyperuricaemia were present in the blood sampled four months after hepatectomy. Except for azurophilia, the other values of the blood profile were within the expected range for a healthy snake seven months after surgery, indicating full recovery. This is the first detailed report of a successful central resection of a large pathologically changed part of the liver in snakes which was diagnosed as biliary cystadenoma.
\end{abstract}

Reptile, liver, tumour, soft tissue surgery

Numerous reptilian neoplasms have been reported so far, but the majority was based on post mortem findings with minimum of clinical information. Most data on the occurrence of tumours in reptiles were based on single-case reports (Hruban and Maschgan 1982; Majeed et al. 1985; Mauldin and Done 2006; Bera et al. 2008). Detailed studies on neoplasia in ophidian collections of zoological parks (Montali 1980; Griner 1983; Ramsay et al. 1996; Catão-Dias and Nichols 1999; Sykes and Trupkiewicz 2006) demonstrated that the incidence of tumours in captive snakes is increasing and probably a result of longer life span due to improved husbandry and management (Ram say et al. 1996). Among ophidian species, frequently reported neoplasms include mesenchymal (Hubbard et al. 1983), epithelial (Montali 1980; Ramsay et al. 1996), and lymphoid/haematopoietic (Catão-Dias and Nichols 1999; Sykes and Trupkiewicz 2006). In snakes the liver has been found to be an organ frequently affected with neoplasms (Garner et al. 2004; Sykes and Trupkiewicz 2006). Very few reports describe the detection of biliary cystadenoma or bile duct adenoma in reptiles (Cowan 1968; Zwart and Harshbarger 1991; Sykes and Trupkiewicz 2006) detected in post mortem examinations of ophidian collections in zoological parks.

Address for correspondence:

Prof. MVDr. Zdeněk Knotek, CSc.

Avian and Exotic Animal Clinic Faculty of Veterinary Medicine

University of Veterinary and Pharmaceutical Sciences

Palackého tř. 1/3, 61242 Brno, Czech Republic 
The aim of this study was to present the clinical and pathological features of the Plains garter snake (Thamnophis sirtalis radix) with biliary cystadenoma along with the diagnostic and therapeutic approaches and the outcome.

\section{Case history}

A four-year-old, captive-bred, female Plains garter snake (Thamnophis sirtalis radix) from the Vivarium of the Museum of Natural History in Vienna was presented to the Clinic for Avian, Reptile and Fish Medicine of the University of Veterinary Medicine, Vienna, Austria, due to a distension of the midbody. The snake belonged to a collection of Plains garter snakes which now breed in the fifth generation in the Museum of Natural History without any observed indications of inbreeding depression. The snake was kept together with three male and two female conspecifics in a terrarium of $110 \times 95 \times 120 \mathrm{~cm}$ in size, which was illuminated and heated with HQI lamps $13 \mathrm{~h} /$ day. Gravel (1 cm in size) was used as substrate. Food was provided every $2^{\text {nd }}$ day in the form of defrosted stint earthworms and infrequently living freshwater fishes (mainly Pseudorasbora parva). Water was provided in a $20 \mathrm{~cm} \times 15 \mathrm{~cm}$ basin with the water level of $5 \mathrm{~cm}$.

According to the owner, visible swelling of the body developed within one week. On physical examination, the snake was in a good condition, weighing $208 \mathrm{~g}$ with a total length of $123 \mathrm{~cm}$, still eating and active. No signs of any of depression were observed. The swelling (Plate VI, Fig. 1) was about $5 \mathrm{~cm} \times 3 \mathrm{~cm} \times 3 \mathrm{~cm}$ in size, soft, slightly fluctuating and localised in the middle third of the snake. The rest of the physical exam was unremarkable.

\section{Diagnostic techniques}

Radiographs confirmed massive enlargement of soft tissue at the caudal border of the lung and the oesophagus, in the expected region of the liver and stomach (Plate VI, Fig. 2). As it was not possible to identify the origin of the swelling by this investigation, an upper gastrointestinal contrast radiographic study using 25\% barium sulphate (Micropaque susp., Delpharm, France) as the contrast medium was conducted. By means of this technique an envolvement of the oesophagus and stomach was excluded (Plate VI, Fig. 3). Subsequently, aspiration of the distension was performed yielding $8 \mathrm{ml}$ of clear, acellular straw coloured fluid reducing the swelling to a third of its original size. The fluid was analyzed for the presence of bacteria, fungi and parasites, but none of these organisms could be detected. In addition, faecal staining, direct mount, and centrifugation assisted flotation revealed no findings, either.

\section{Hepatectomy}

An exploratory coeliotomy was elected to obtain a definite diagnosis. The snake was premedicated with butorphanol (2 mg/kg i.m., Butomidor ${ }^{\circledR}$, Richter Pharma AG, Austria). After $20 \mathrm{~min}$, anaesthesia was induced by mask with $5 \%$ isoflurane (Isofluran ${ }^{\circledR}$, Baxter $\mathrm{GmbH}$, Austria) mixed with oxygen $(0.21 / \mathrm{min})$ followed by tracheal intubation. Anaesthesia was maintained throughout the following surgical procedure with $2 \%$ isoflurane and oxygen $(0.2 \mathrm{l} / \mathrm{min})$ by manual positive pressure ventilation at a rate of an average of $4 / \mathrm{min}$.

The snake was positioned in right lateral recumbency and fixed to a sterile drape. After skin disinfection with a $70 \%$ ethanol solution, coeliotomy was performed by a left lateral approach where scutes and scales are in apposition. Once entrance to the coelomic cavity was attained, an extremely distended part of the liver with numerous small green cysts was observed (Plate VI, Fig. 4). The whole liver was gently elevated out of the coelomic cavity in order to visualize the dimension of pathological changes. The central part of the liver (about $5 \mathrm{~cm}$ in length) was distended and deformed with cysts (Plate VII, Fig. 5). Cranially and caudally to this lesion the liver appeared macroscopically normal. Therefore, only the central part of the liver was dissected. At first two vascular clamps were placed temporarily 
cranially and caudally to the changed part of the organ. Then strong ligatures were situated around each of these sides allowing complete excision of the cystic part of the liver dividing the remaining organ into a cranial and caudal part. The resected specimen was placed immediately into a $10 \%$ neutral-buffered formalin solution for further histological investigation. The green-coloured cysts had smooth surfaces, were of different sizes and each of them was filled with either clear straw coloured or haemorrhagic fluid. Finally, the vascular clamps were released and occlusive ligatures tightened and controlled. The cut surfaces of the remaining cranial and caudal parts of the liver were washed with a sterile $0.9 \% \mathrm{NaCl}$ solution in order to control any small hidden bleeding. At the end of the surgical procedure the pleuroperitoneum was closed with a single simple continuous pattern of absorbable 4-0 polyglactin 910 (Vicryl ${ }^{\circledR}$ Ethicon, Germany). Thereafter, the same material was used for closing the skin in a continuous everting pattern.

\section{Postoperative care and recovery}

The snake tolerated the procedure well and recovered rapidly from surgery. Marbofloxacin (10 mg/kg i.m. per day, Marbocyl 2\% ${ }^{\circledR}$, Vétoquinol, France) and fluids (20 ml $/ \mathrm{kg}$ SC Ringer's solution with 5\% glucose) were administered to the animal for 8 days. Postoperative analgesia was provided by oral application of meloxicam $(0.2 \mathrm{mg} /$ $\mathrm{kg}$, Metacam ${ }^{\circledR}$, Boehringer Ingelheim Vetmedia $\mathrm{GmbH}$, Germany) once a day. The snake started to feed on fish two days later and was active as before the hepatectomy. After 8 days of hospitalization the snake was released back to the owner.

\section{Follow-up status}

Two months after surgery, a physical check up of the snake and suture material removal were scheduled. During the check up the snake was very active and in a good condition. A small volume of blood $(0.4 \mathrm{ml})$ was collected from the ventral tail vein for haematology and plasma chemistry evaluation. The blood profile values were within the expected range for a healthy snake (Diethelm and Stein 2006) except for hypoproteinaemia (Table 1) and altered activity of transaminases (lactate dehydrogenase, LDH). Within the next physical check ups (4 and 7 months after hepatectomy) the snake remained very active and in a good condition (body weight of $262 \mathrm{~g}$ ). Blood samples were collected for haematology and plasma chemistry evaluation and radiographic studies were conducted to control the shape

Table 1. Blood profile of the Plains garter snake (Thamnophis sirtalis radix), two, four and seven months after central hepatectomy.

\begin{tabular}{lccccccc}
\hline Plasma chemistry & 2 months & 4 months & 7 months & Haematology & 2 months & 4 months & 7 months \\
\hline Total protein (g/dl) & 2.94 & 6.4 & 5.84 & Haemoglobin (g/dl) & ND & 7.66 & 10.66 \\
BUN (mg/dl) & ND & 8.0 & 3.5 & PCV (\%) & ND & 23 & 26 \\
Uric acid (mg/dl) & 6.1 & 28.6 & 4.50 & RBCs (T/l) & ND & 0.640 & 0.680 \\
Calcium (mmol/l) & 2.46 & 3.76 & 3.85 & WBCs (G/l) & ND & 3.00 & 2.50 \\
Phosphorus (mmol/l) & 0.73 & 1.69 & 0.89 & Heterophils (\%) & 70 & 35 & 30 \\
ALP (IU/l) & ND & 75 & 53 & Eosinophils (\%) & 0 & 0 & 0 \\
ALT (IU/l) & ND & 13 & 24 & Basophils (\%) & 0 & 5 & 5 \\
AST (IU/l) & 56 & 13 & 21 & Monocytes (\%) & 0 & 3 & 0 \\
GLDH (IU/l) & 70.75 & 116.23 & 36.31 & Azurophils (\%) & 10 & 46 & 48 \\
LDH (IU/l) & 1110 & 234 & 461 & Lymphocytes (\%) & 20 & 11 & 17 \\
CK (IU/l) & ND & 1849 & 3042 & & & &
\end{tabular}

$\mathrm{ND}=$ not done, BUN - urea, ALP - alkalic phosphatase, ALT - alanine aminotransferase, AST - aspartate aminotransferase,

GLDH - glutamate dehydrogenase, LDH - lactate dehydrogenase , CK - creatinine phosphokinase 
of the liver field. Four months after surgery, the blood profile values of the snake remained within the expected range for a healthy snake except for the presence of azurophilia and hyperuricaemia (Table 1). The high concentration of uric acid $(28.6 \mathrm{mg} / \mathrm{dl})$ was due to recent feeding. Seven months after surgery the blood profile values of the snake were also within the expected range for a healthy snake (Table 1) except for the still persisting azurophilia.

\section{Histological examination}

Tissue blocks of the fixed liver sample were embedded in paraffin wax, sectioned at 3 $\mu \mathrm{m}$ and routinely stained with haematoxylin and eosin. The lesions consisted of multiple, sometimes multichambered cysts of various sizes (Plate VII, Fig. 6). The lining epithelium was non ciliated, cuboidal to isoprismatic, and sometimes columnar. The epithelium was bordered by a layer of fibrous connective tissue of varying thickness. Mitotic figures and other signs of malignancy could not be observed. Adjacent liver parenchyma showed atrophy due to compression. Furthermore, the liver contained few large blood vessels and bile ducts in fibrous stroma, which results from pressure atrophy. The diagnosis was defined as biliary cystadenoma.

\section{Discussion}

To the authors' knowledge this is the first reported case of biliary cystadenoma in a Plains garter snake, its ante mortem diagnosis and a successful surgical treatment.

Midbody distension in snakes is a symptom with a wide range of possible causes. In the present case, visible body distension was the only clinical sign which did not seem to irritate the snake. The same was observed in an adult female king snake (Lampropeltis getulus) some weeks before it died due to a malignant liver cell tumour (Majeed et al. 1985). Biliary cystadenomas are diagnosed incidentally, by palpation of the abdominal mass or in radiologic studies, laparotomy or post mortem (Catão-Dias and Nichols 1999; Mauldin and Done 2006; Sykes and Trupkiewicz 2006). A contrast radiographic study performed in the present case revealed that the source of the swelling was not the upper digestive tract. This finding allowed us to exclude an infection with Cryptosporidium serpentis, a protozoon that causes gastric hyperplasia in snakes, characterized by noticeable body swelling (Godshalk et al. 1986) similar to the present one. As a further diagnostic approach the distension of the snake was punctured and acellular clear yellowish fluid was collected. This procedure helped to rule out the presence of an abscess, haematoma or a parasitic cyst but still did not allow a definite diagnosis. Thus, an exploratory coeliotomy was performed revealing the cause of the body distension, a pathologically changed central part of the liver with numerous green cysts. Fluids collected from some cysts were all straw coloured or haemorrhagic. We found only two studies on snakes when a partial hepatectomy was performed in order to remove a mass in the region of the liver histopathologically diagnosed as hepatocellular adenoma in Massassauga rattlesnake (Sistrurus catenatus catenatus) (Hruban and Maschgan 1982) or bile duct carcinoma in a garter snake (Thamnophis sirtalis) (Zwart and Harshbarger 1991). The rattlesnake recovered well after hepatectomy (description of the procedure is missing), but died seven months later due to an extension of the adenoma outside the remaining liver. In case of the garter snake a circumscribed mass at the caudal tip of the liver was removed and the snake recovered well.

In the present study, the technique of temporary vascular occlusion of the liver and guillotine method in Thamnophis sirtalis radix offered a feasible approach to hepatic dissection in the patient. The plains garter snake has been checked up on regular basis. Acute inflammation of the liver is expected to result in a dramatic heterophilia and azurophilia, with a total white blood cell count above the commonly observed range (Divers 2000), 
but except for azurophilia the other values of the blood profile were within the expected range for a healthy snake seven months after surgery. The patient was in a good body condition, active and no recurrence of cysts or other pathological changes have been noticed so far. Hence, this is the first detailed report of a successful central resection of a large pathologically changed part of the liver which was diagnosed as biliary cystadenoma in snakes.

\section{References}

Bera MM, Veeramachaneni DN, Pandher K 2008: Characterization of a biphasic neoplasm in a Madagascar tree boa (Sanzinia madagascariensis). Vet Pathol 45: 259-263

Catão-Dias JL, Nichols DK 1999: Neoplasia in snakes at the National Zoological Park, Washington, DC (19781997). J Comp Pathol 120: 89-95

Cowan DF 1968: Diseases of captive reptiles. J Am Vet Med Assoc 153: 848-859

Diethelm G, Stein G 2006: Hematologic and blood chemistry values in reptiles. In Reptile Medicine and Surgery. $2^{\text {nd }}$ ed. Ed D.R. Mader, St. Louis, Saunders Elsevier. 1103-1118

Divers SJ 2000: Reptilian liver and gastrointestinal testing. In Laboratory Medicine. Avian and Exotic Pets. Ed A.M. Fudge, Philadelphia, W.B. Saunders Co. 205-209

Garner MM, Hernandez-Divers SM, Raymond JT 2004: Reptile neoplasia: a retrospective study of case submissions to a specialty diagnostic service. Vet Clin N Am - Exot Anim Pract 7: 653-671

Godshalk CP, Maccoy DM, Patterson JS, McKiernan BC 1986: Gastric hypertrophy associated with cryptosporidiosis in a snake. J Am Vet Med Assoc 189: 1126-1128

Griner LA 1983: Pathology of zoo animals. Zoological Society of San Diego, San Diego, California, pp. 60-64

Hruban Z, Maschang ER 1982: A hepatocellular adenoma in a rattlesnake. J Comp Pathol 92: 429-435

Hubbard GB, Schmidt RE, Fletcher KC 1983: Neoplasia in zoo animals. J Zoo Anim Med 14: 33-40

Majeed S, Cooper JE, Abbott D 1985: A malignant liver cell tumour in a king snake (Lampropeltis getulus). J Comp Pathol 95: 127-129

Mauldin GN, Done LB 2006: Oncology. In Reptile Medicine and Surgery. 2nd edn. Ed D.R. Mader. Philadelphia, Pennsylvania, W.B. Saunders Co, pp. 299-322

Montali RJ 1980: An overview of tumors in zoo animals. In Comparative Pathology of Zoo Animals. Eds R.J. Montali, G. Migaki. Washington, D.C., Smithsonian Institution Press, pp. 531-542

Ramsay EC, Munson L, Lowenstin L, Fowler ME 1996: A retrospective study of neoplasia in a collection of snakes. J Zoo Wildlife Med 27: 28-34

Sykes JM, Trupkiewicz JG 2006: Reptile neoplasia at the Philadelphia Zoological Garden, 1901-2002. J Zoo Wildlife Med 37: 11-19

Zwart P, Harsbarger JC 1991: A contribution to tumors in reptiles. In Proceedings of the $4^{\text {th }}$ International Colloquium on Pathology of Reptiles and Amphibians. Bad Nauheim, Germany, pp. 219-224 
Plate VI

Knotek Z. et al.: Partial ... pp. 433-437

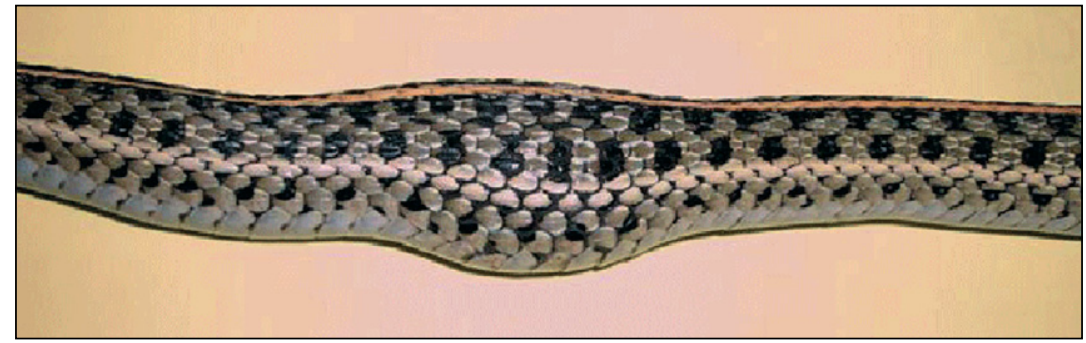

Fig. 1. Body swelling localised in the middle third of the Plains garter snake.

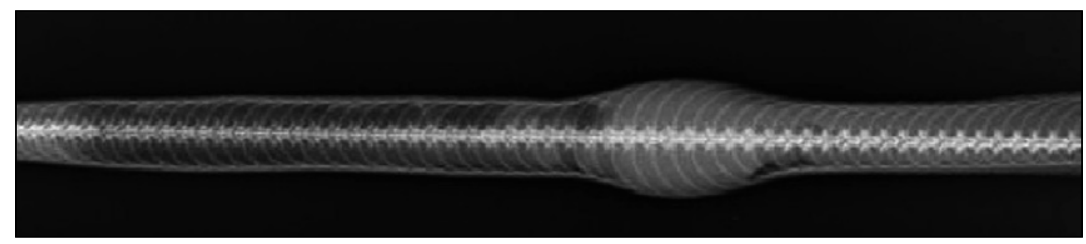

Fig. 2. Dorsoventral radiographic study in the Plains garter snake.

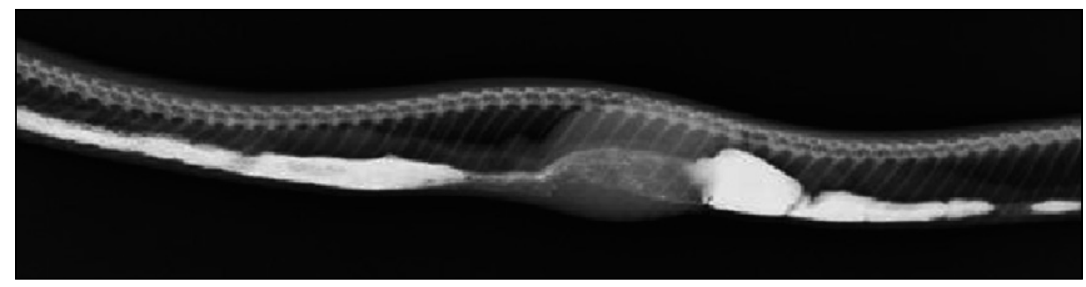

Fig. 3. Contrast radiographic study (25\% barium sulphate) in the Plains garter snake.

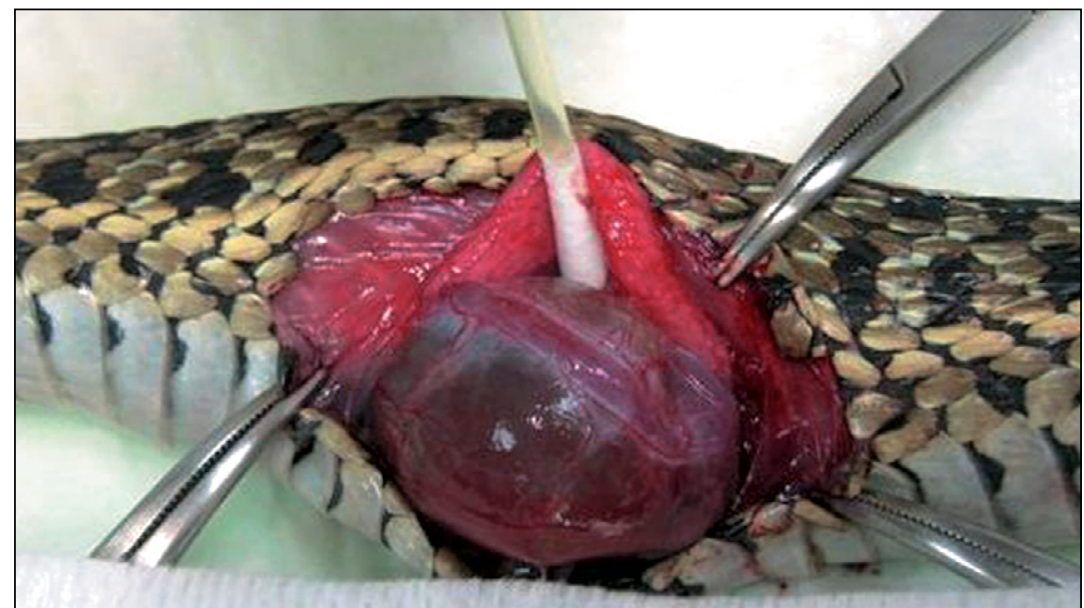

Fig. 4. Coeliotomy performed by a left lateral approach in the Plains garter snake. 


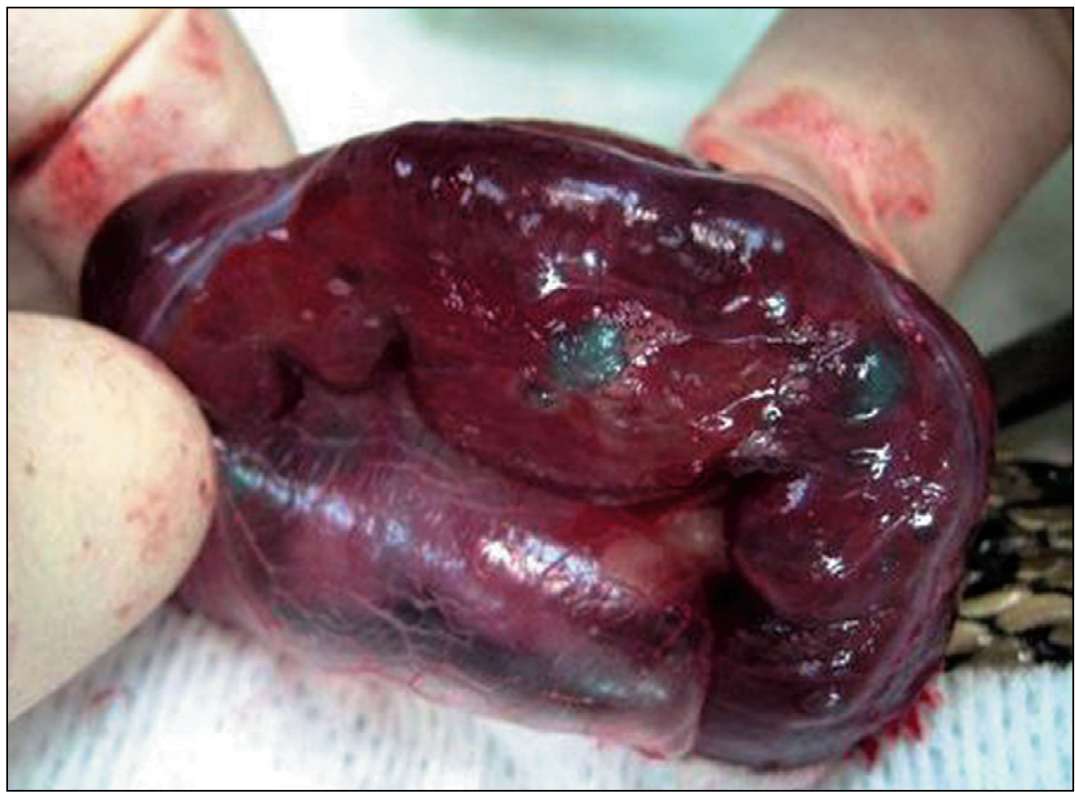

Fig. 5. Distended part of the Plains garter snake liver with numerous small green cysts.

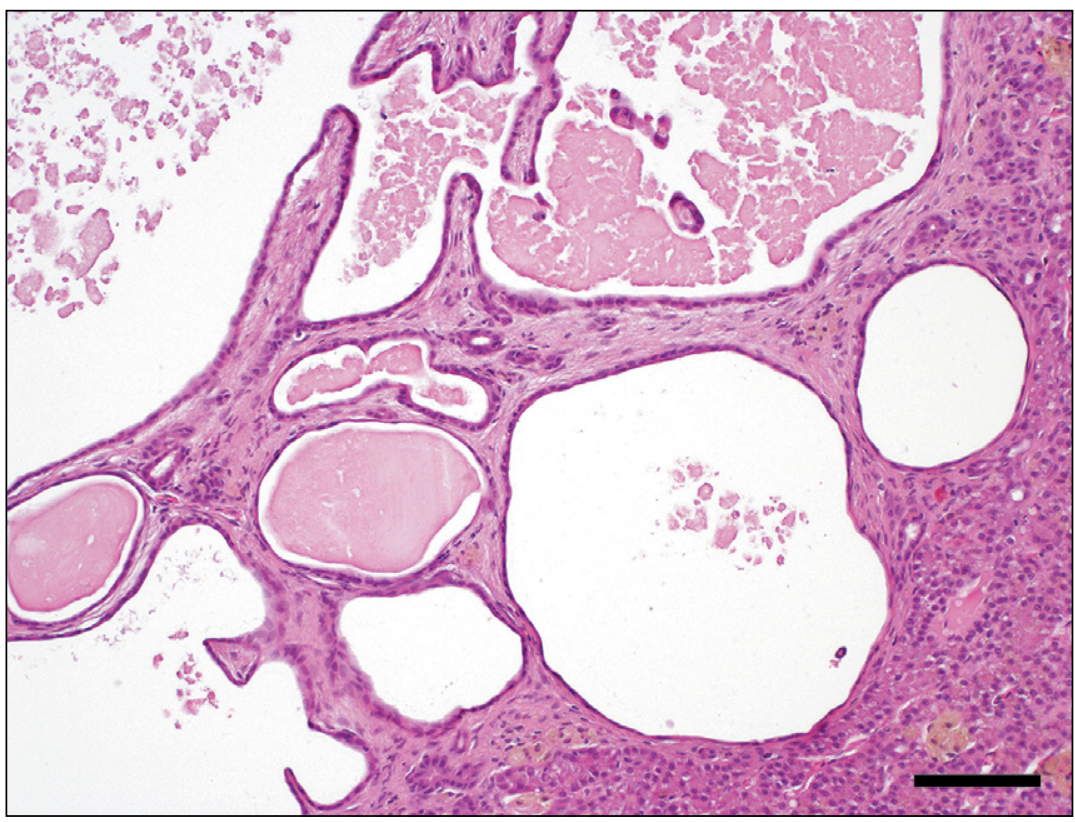

Fig. 6. Histopathology section of the Plains garter snake liver showing cuboidal epithelium and surrounding fibrous connective tissue; in cysts some eosinophilic proteinous fluid can be observed. Haematoxylin and eosin stain; bar $=100 \mu \mathrm{m}$. 